Poincare Journal of Analysis E Applications

Vol. 2014 (1), Pages 1- 8

CPoincare Publishers

\title{
ON A GENERALIZED PRODUCT SUMMABILITY OF FOURIER SERIES
}

\author{
XHEVAT Z. KRASNIQI \\ Date of Receiving : : April 27, 2014 \\ Date of Revision : : May 19, 2014 \\ Date of Acceptance : June 19, 2014
}

Abstract. In this paper a generalized product of summability is introduced in order to make an advanced study on the special topic of summability. In addition, employing that product we establish a new theorem regarding to summability of Fourier series.

\section{Introduction and Known Results}

Let $f(t)$ be a periodic function with period $2 \pi$ and integrable over the interval $(-\pi, \pi)$ in the sense of Lebesgue. Let

$$
f(t) \sim \frac{a_{0}}{2}+\sum_{n=1}^{\infty}\left(a_{n} \cos n t+b_{n} \sin n t\right)
$$

be its Fourier series.

For two sequences of real or complex numbers $p=\left\{p_{n}\right\}$ and $q=\left\{q_{n}\right\}$, let

$$
\begin{aligned}
P_{n} & =p_{0}+p_{1}+p_{2}+\cdots+p_{n}=\sum_{v=0}^{n} p_{v}, \text { for all } n, \\
Q_{n} & =q_{0}+q_{1}+q_{2}+\cdots+q_{n}=\sum_{v=0}^{n} q_{v}, \text { for all } n,
\end{aligned}
$$

and let the convolution $(p * q)_{n}$ be defined by

$$
R_{n}:=(p * q)_{n}:=\sum_{v=0}^{n} p_{v} q_{n-v} .
$$

2010 Mathematics Subject Classification. 40G05, 42A24, 40C05.

Key words and phrases. Abel's lemma, Summability method, Fourier series, Riemann-Lebesgue theorem.

The author would like to express many thanks to the anonymous referee for her/his valuable suggestions which definitely improved this paper.

Communicated by: L.K. Vashisht 